\title{
Epidermal growth factor as a reliable marker of necrotizing enterocolitis in preterm neonates
}

Na Mi Lee, MD, PhD

Department of Pediatrics, Chung-Ang University Hospital, College of Medicine, Chung-Ang University, Seoul, Korea

Necrotizing enterocolitis (NEC) is the most common surgical gastrointestinal emergency in premature neonates. ${ }^{1,2)}$ The prevalence of NEC is $7 \%$ in infants with a birth weight of 500 $1,500 \mathrm{~g}$ in the United States and Canada, with a mortality rate of approximately $42 \% .{ }^{3)}$ Globally, the overall mortality rate is $20 \%$ $40 \% .{ }^{4)}$ The clinical signs of NEC can vary in severity, ranging from nonspecific symptoms, such as apnea and temperature instability, to specific symptoms, such as abdominal distension, bloody stools, pneumatosis intestinalis, and shock. ${ }^{2)}$ Medical treatments for NEC consist of broad-spectrum antibiotics, volume loading, and bowel rest. However, many patients with NEC require surgical removal of the necrotic bowel and develop short bowel syndrome with prolonged medical expenses and chronic gastrointestinal difficulties. Furthermore, surgical NEC is a significant predictor of neurodevelopmental morbidity in preterm infants. ${ }^{5)}$ The exact pathogenesis of NEC remains poorly understood, but its etiology is possibly multifactorial. The treatment strategies are mainly supportive.

The epithelial lining of the intestine provides the first line of defense against bacteria, viruses, and toxins. Epidermal growth factor (EGF) is essential for epithelial cell proliferation, decreases inflammatory mediator expression, and reduces epithelial apoptosis. ${ }^{3)}$ Many studies have examined the effect of EGF in NEC. Recent studies have shown that exogenous EGF administration reduces mucosal histological damage in animal models. ${ }^{6}$ In addition, EGF treatment in NEC normalizes occludin and claudin expressions. ${ }^{7}$ All the above-mentioned studies were conducted in animals, while few have been conducted in humans.

Ahmed and $\mathrm{Kamel}^{8)}$ presented the correlation between serum EGF levels and NEC in neonates. In this prospective study, the mean serum EGF levels were significantly lower in the NEC group than in the sepsis or control groups, and there was a significant negative association between EGF levels and gestational age as predictors of NEC development. He et al. ${ }^{9)}$ reported that the breast milk of mothers of premature infants contains 50\%-80\% more EGF than that of mothers of fullterm infants. These results suggest that NEC is correlated with lower EGF levels and younger gestational age and that breast milk of mothers of premature infants is protective against NEC. ${ }^{3,10)}$ Furthermore, Ahmed and Kamel ${ }^{8)}$ presented the cutoff serum EGF value using receiver operating characteristic curves that could identify it as a NEC biomarker.

Early diagnosis and treatment are very important in NEC. EGF could be a reliable NEC biomarker in preterm infants. Additional research is needed to confirm the application of EGF as an early diagnostic tool for NEC.

Conflicts of interest

No potential conflict of interest relevant to this article was reported.

See the article "The relation between serum levels of epidermal growth factor and necrotizing enterocolitis in preterm neonates" via https://doi.org/10.3345/kjp.2018.07108.

\section{References}

1. Yang J, Su Y, Zhou Y, Besner GE. Heparin-binding EGF-like growth factor (HB-EGF) therapy for intestinal injury: application and future prospects. Pathophysiology 2014;21:95-104.

2. Coursodon CF, Dvorak B. Epidermal growth factor and necrotizing enterocolitis. Curr Opin Pediatr 2012;24:160-4.

3. Isani MA, Delaplain PT, Grishin A, Ford HR. Evolving understanding of neonatal necrotizing enterocolitis. Curr Opin Pediatr 2018;30:417-23.

4. Wei J, Zhou Y, Besner GE. Heparin-binding EGF-like growth factor and enteric neural stem cell transplantation in the prevention of experimental necrotizing enterocolitis in mice. Pediatr Res 2015;78:29-37.

5. Halpern MD, Denning PW. The role of intestinal epithelial barrier function in the development of NEC. Tissue Barriers 2015;3:e1000707.

6. Warner BW, Warner BB. Role of epidermal growth factor in the pathogenesis of neonatal necrotizing enterocolitis. Semin Pediatr Surg 2005;14: 175-80.

7. Khailova L, Dvorak K, Arganbright KM, Williams CS, Halpern MD, Dvorak B. Changes in hepatic cell junctions structure during experimental necrotizing enterocolitis: effect of EGF treatment. Pediatr Res 2009;66: 140-4.

8. Ahmed HM, Kamel NM. The relation between serum levels of epidermal growth factor and necrotizing enterocolitis in preterm neonates. Korean J Pediatr 2019;62:307-11.

9. He Y, Schmidt MA, Erwin C, Guo J, Sun R, Pendarvis K, et al. Transgenic

Corresponding author: Na Mi Lee, MD, PhD. Department of Pediatrics, Chung-Ang University Hospital, 102 Heukseok-ro, Dongjak-gu, Seoul 06973, Korea 凶E-mail: piena81@caumc.or.kr, https://orcid.org/0000-0003-0580-8677

Received: 3 May, 2019, Revised: 6 August, 2019, Accepted: 18 September, 2019

This is an open-access article distributed under the terms of the Creative Commons Attribution Non-Commercial License (http://creativecommons.org/licenses/bync/4.0/) which permits unrestricted non-commercial use, distribution, and reproduction in any medium, provided the original work is properly cited.

Copyright (c) 2020 by The Korean Pediatric Society 
soybean production of bioactive human epidermal growth factor (EGF). PLoS One 2016;11:e0157034.

10. Isani M, Illingworth L, Herman E, Schmidt M, Barron L, Bowling J, et al.
Soybean-derived recombinant human epidermal growth factor protects against experimental necrotizing enterocolitis. J Pediatr Surg 2018;53: 1203-7. 